\title{
A Pilot Randomized, Controlled Study of Nanocrystalline Silver, Manuka Honey, and Conventional Dressing in Healing Diabetic Foot Ulcer
}

\author{
Ka-Kit Tsang, ${ }^{1,2}$ Enid Wai-Yung Kwong, ${ }^{3}$ Tony Shing-Shun To, ${ }^{4}$ \\ Joanne Wai-Yee Chung, ${ }^{5}$ and Thomas Kwok-Shing Wong ${ }^{6}$ \\ ${ }^{1}$ O\&T Department, Queen Elizabeth Hospital, Kowloon, Hong Kong \\ ${ }^{2}$ Department of Nursing, The Hong Kong Polytechnic University, Kowloon, Hong Kong \\ ${ }^{3}$ School of Nursing, Tung Wah College, Kowloon, Hong Kong \\ ${ }^{4}$ Department of Health Technology \& Informatics, The Hong Kong Polytechnic University, Kowloon, Hong Kong \\ ${ }^{5}$ Faculty of Liberal Arts and Social Sciences, The Education University of Hong Kong, Tai Po, Hong Kong \\ ${ }^{6}$ Ginger Knowledge Transfer and Consultancy Limited, Kowloon, Hong Kong
}

Correspondence should be addressed to Ka-Kit Tsang; kktsang3@netvigator.com

Received 25 September 2016; Revised 3 December 2016; Accepted 13 December 2016; Published 25 January 2017

Academic Editor: Elia Ranzato

Copyright (C) $2017 \mathrm{Ka}$-Kit Tsang et al. This is an open access article distributed under the Creative Commons Attribution License, which permits unrestricted use, distribution, and reproduction in any medium, provided the original work is properly cited.

\begin{abstract}
Nanocrystalline silver ( $\mathrm{nAg}$ ) and Manuka honey (MH) dressing have increasing popularity for treating diabetic foot ulcer (DFU). This study was an open-label randomized controlled trial with three parallel groups design in examining the preliminary effectiveness of $\mathrm{nAg}$ against $\mathrm{MH}$ and conventional dressing in healing DFU in terms of ulcer healing, ulcer infection, and inflammation. 31 participants (11 in the $\mathrm{nAg}$ group, 10 in the $\mathrm{MH}$ group, and 10 in the convention group) diagnosed with type 2 diabetes were enrolled. Wound cleaning, debridement, and topical dressing application were performed according to the group allocation in each visit at weeks $1,2,3,4,6,8,10$, and 12 . The results found that the proportions of complete ulcer healing were $81.8 \%, 50 \%$, and $40 \%$ in the $\mathrm{nAg}, \mathrm{MH}$, and conventional groups, respectively. The ulcer size reduction rate was potentially higher in the nAg group (97.45\%) than the MH group $(86.21 \%)$ and the conventional group (75.17\%). In bacteriology, nAg showed a greater rate of microorganism reduction although it was not significant. To conclude, $\mathrm{nAg}$ alginate was potentially superior to $\mathrm{MH}$ and conventional dressing in healing diabetic foot ulcer in terms of ulcer size reduction rate.
\end{abstract}

\section{Introduction}

Diabetes mellitus (DM) is a common worldwide problem and diabetic foot ulcer (DFU) is among the most complex and heterogeneous complications in patients with DM [1]. It is estimated that DM affects $8.3 \%$ of the global population or 382 million of people [2]. This number continues to grow, making DFU a major public health problem. The cumulative incidences of patients who developed a new appearance of foot ulcer after 1,3 , and 5 years were $27.3 \%, 57.2 \%$, and $76.4 \%$, respectively, leading to the corresponding reamputation rates of $12.5 \%, 22.3 \%$, and $47.1 \%$ [3].

DFU is also associated with the disruption of normal wound healing mechanism. The persistent inflammation in
DFU is likely due to bacterial contamination and subsequent infections [4]. Furthermore, free radicals (superoxide anion and hydroxyl radial) are formed at disproportionately high levels by the formation of advanced glycation end products (AGEP) in people with diabetes [5]. The accumulation of AGEP causes the upregulation of proinflammatory cytokines [such as interleukin-1 (IL-1) and tumor necrosis factoralpha (TNF- $\alpha$ )]. Matrix metalloproteinases (MMPs), which are also produced in wounds, degrade extracellular matrix (ECM) and inhibit growth factors through the formation of reactive oxygen species (ROS) [6]. A topical intervention method that can effectively kill the bacteria and downregulate the MMP and proinflammatory cytokines production is therefore important in the treatment of DFU. 
Both paraffin tulle and gauze are conventionally used on DFU. Nevertheless, nanocrystalline silver (nAg) dressing and Manuka honey $(\mathrm{MH})$ dressing have become popular recently in view of the increased risk of multidrug-resistant bacteria in the environment [7]. In vitro evidence indicates that $\mathrm{nAg}$ has a unique antibacterial action through anchoring to the bacterial cell wall, causing structural damage altering the membrane permeability [8]. Moreover, recent in vivo studies found that the anti-inflammatory action of $\mathrm{nAg}$ could effectively downregulate the level of both MMPs and cytokines [9]. The antibacterial action of $\mathrm{MH}$ is mainly based on its acidic nature [10], hyperosmolality to dehydrate bacteria [11], and the phytochemical factor, methylglyoxal (MGO) [12]. Recent in vitro studies further revealed that the cationic and noncationic compounds [13] as well as leptosin [14] contributed to the antibacterial activity in $\mathrm{MH}$. In addition, the flavonoids found in $\mathrm{MH}$ could counteract effectively the oxidative stress induced by AGEP in diabetics [15].

Based on the abovementioned evidence, $\mathrm{nAg}$ and $\mathrm{MH}$ may be able to target the infection and inflammation of DFU. Despite the fact that $\mathrm{nAg}$ and $\mathrm{MH}$ are increasingly used nowadays, there is limited clinical evidence of high quality to support our practice. Only two low quality randomized controlled trials conducted on $\mathrm{MH}$ for DFU are available for the past 10 years $[16,17]$. To date, merely one case study series concerning the effects of $\mathrm{nAg}$ on DFU was published [18]. It can be considered that $\mathrm{MH}$ has stronger evidence than $\mathrm{nAg}$ in healing DFU. Most importantly, no comparison study has been conducted to investigate the effectiveness between $\mathrm{nAg}$ and $\mathrm{MH}$ on DFU. A research gap between the fundamental science and clinical evidence on the DFU healing effects of $\mathrm{nAg}$ and $\mathrm{MH}$ exists. This was the first pilot randomized controlled trial, which aimed to address this missing link and to investigate the effectiveness of $\mathrm{nAg}$ against $\mathrm{MH}$ and conventional dressing in healing DFU. We hypothesized that nAg dressing would be more effective than $\mathrm{MH}$ dressing and conventional dressing on DFU healing.

\section{Methods}

2.1. Study Design. In this open-label prospective pilot randomized control, a study of three parallel groups was designed to compare the clinical effectiveness and the changes in biochemical concentration in wound fluid of $\mathrm{nAg}$ against $\mathrm{MH}$ dressing and conventional dressing (paraffin tulle) in treating DFU (trial registration: ClinicalTrial.gov NCT02577900). The trial was conducted in compliance with the Declaration of Helsinki. The approval was granted by local university's and hospital's human ethics committees. Informed consent was obtained from every subject before the commencement of the study.

2.2. Subjects. The target participants were screened in the orthopedic department of two regional hospitals and one general outpatient clinic (GOPC). Eligible potential subjects were recruited according to the selection criteria after they had been discharged from hospital. All the subjects were referred to and intervened in an outpatient orthopedic nurseled clinic in an acute regional tertiary hospital of Hong Kong. The inclusion criteria included subjects living in community settings, being type 2 DM patients, age 40 or above with foot ulcer at or below malleolar region, wound size equal to or larger than $1 \mathrm{~cm}$ in diameter, and no foreseeable surgery within the 12 -week study period through clinician assessment. The exclusion criteria included HbAlc level $\geq$ $10 \%$; ankle brachial index $\leq 0.4$; ulcer with bone or joint exposed; osteomyelitis; severe wound infection [according to the Infectious Diseases Society of America (ISDA) and International Working Group of Diabetic Foot (IWGDF) classification of diabetic foot infection] [19]; known allergy to $\mathrm{nAg}$ or $\mathrm{MH}$; known case of venous ulcer, tumor, or autoimmune diseases.

2.3. Randomization. The participants were randomized into three groups by online randomization software (http://www .randomization.com). A sequence of randomized group numbers (i.e., 1 to 3 ) was generated by research assistant $A$ and the randomized group numbers were put into the opaque, sealed envelopes in chronological order. The numbered sealed envelopes were then passed to the first author for enrollment of participants.

2.4. Interventions. All participants attended weekly the nurse clinic for follow-up by the first author in the first four weeks and biweekly till the 12 th week of the follow-up period. There were eight clinical attendances in total. Regarding the offloading strategy, customer-made insole (CMI) was provided to participants who had plantar ulcer. Stick and heel walking methods were educated to these participants. Callus debridement was performed by the first author in each clinic visit so as to decrease the local pressure. The ulcer was cleansed and nonviable tissues and biofilm were debrided every time by the first author if necessary after obtaining the verbal consent. All exposed tendons and avascular tissues were also stimulated with needle or blade until they bled. This intervention was used as cellular recruitment to the local area for angiogenesis and granulation formation. Topical dressing was then applied according to the randomization sequence.

The strength of evidence was given by the test treatment of $\mathrm{nAg}$ dressing (Acticoat ${ }^{\mathrm{TM}}$ absorbent, Smith \& Nephew, London, United Kingdom). The active comparator was $\mathrm{MH}$ dressing (Medihoney ${ }^{\mathrm{TM}}$ gel sheet, Derma Sciences, Toronto, Canada), whereas the control treatment was the paraffin tulle (Jelonet $^{\mathrm{TM}}$, Smith \& Nephew, London, United Kingdom). As maintained by the prescription of the dressing materials, community nurses or nurses in GOPC undertook simple dressing change. Oral antibiotics were prescribed if the participants had a moderately infected DFU. If the infection was severe, they were recommended to be admitted into hospital and receive intravenous antibiotic injection, and their participation in the study was terminated.

2.5. Outcome Measures. The primary outcome of the study was cumulative ulcer healing incidence after 12 weeks of treatment. The secondary outcomes were the ulcer size reduction rate, bacteriology, and clinical signs of wound 
infection over the 12 weeks as well as the change of TNF- $\alpha$, IL- $1 \alpha$, and MMP-9 levels in wound fluid during the first four weeks.

2.5.1. Ulcer Healing. Cumulative ulcer healing incidence was the complete ulcer healing, defined as complete wound closure with smooth epithelial surface. The healing status of ulcer was assessed by research assistant B, who was an experienced registered nurse, in each clinic visit.

2.5.2. Ulcer Size Reduction. During each follow-up visit, a digit wound measurement device (Visitrak digital) was used for wound size measurement by research assistant B. She was unaware of the topical treatment option through waiting outside the clinic until the removal and proper cleansing of the wound had been completed by the first author. In order to ensure the blinding of outcome assessment, thorough cleansing with soap and water was performed before dressing. The residue on the scab was removed with scalpel following the debridement procedure. Follow-up with the participants would be discontinued if the wound was considered completely healed or till the end of the 12-week study period.

2.5.3. Bacteriology. Quantitative tissue swab culture was used as a means to determine the wound bioburden. In order to avoid collecting the biofilm, Levine's technique was used. Wound swab culture was taken on the part of the viable wound bed that has no visible biofilm or nonviable tissue. Wound swab was taken by the first author to each participant for every clinic visit (weeks 1, 2, 3, 4, 6, 8, 10, and 12). The types and quantity of bacteria from the wound swab were recorded.

2.5.4. Clinical Signs of Wound Infection. To date, there is still no specific scoring system to classify DFU infection. In this pilot study, the "IDSA and IWGDF classification of diabetic foot infection" was used. Although the categorization was mostly based on the expert opinions, it was the best available classification system specific to DFU. The infection severity categorization as uninfected, mild, moderate, and severe was performed by research assistant B in every clinic visit.

2.5.5. MMPs and Cytokines Concentration. Wound fluid was collected in the first four weeks by the first author. Ulcer was briefly washed with sterile water before fluid collection. Afterwards, an occlusive dressing was applied over the ulcer. Exudate accumulated under the dressing after 30 minutes to 2 hours was collected with a sterile pipette into $0.4 \mathrm{~mL}$ protein Lobind tubes (Eppendorf, Hamburg, Germany). The wound fluid samples were centrifuged at 6,000 revolutions per minute for 30 minutes, aliquoted, and stored at $-20^{\circ} \mathrm{C}$ until further analysis. The protein content of all samples was quantitated and standardized by the BCA Protein assay kit (Pierce Biotechnologies, Rockford, IL, USA) and with bovine serum albumin. The levels of proinflammatory cytokines TNF- $\alpha$ and IL- $1 \alpha$ as well as MMP- 9 in wound fluid were determined by commercial enzyme-linked immunosorbent assay human kit (ELISA) according to the manufacture's protocols (Abcam, USA).
2.6. Statistical Analysis. All the analyses were carried out according to the intention-to-treat principle. SPSS Statistics for Mac version 22 (SPSS Inc, Chicago, Illinois) was used for data analysis. Comparison was made among groups by Fisher's exact test for nominal data and Kruskal-Wallis test for ordinal and scale data. The complete ulcer healing was compared among groups by Kaplan-Meier estimates. General estimating equation (GEE) was applied to compare the ulcer size reduction rate and bacteriology as well as the wound fluid concentration of MMP9, TNF- $\alpha$, and IL- $1 \alpha$ among groups. Statistical significance was set at $p<0.05$ for all tests. Hertzog [20] suggested that the sample size of a pilot study should range from 10 to 40 . However, from the clinical experience of the first author, it is quite hard to find eligible participants. Besides, the main objective of this pilot study was to investigate the preliminary effectiveness of $\mathrm{nAg}$ dressing on DFU. Therefore, 10 per group were targeted in this pilot study and the total number of 30 participants was planned.

\section{Results}

3.1. Baseline Characteristics. This study took place from 1 January 2013 to 31 July 2015. Thirty-one subjects (11 in the nAg group, 10 in the $\mathrm{MH}$ group, and 10 in the conventional group) were recruited. The CONSORT flow diagram is shown in Figure 1.

The baseline on demographics and risk factors of the subject profiles are presented in Table 1 . There were 18 males and 13 females (31 participants in total), 29 of which were recruited from hospitals and 2 from a GOPC. Among all the important parameters affecting DFU healing, there was no statistical difference among groups with $p$ values between 0.143 and 0.948 .

\subsection{Cumulative Healing Incidence}

3.2.1. Intention-to-Treat Principle. The cumulative healing incidence was counted as the incidence of complete ulcer healing in each group (Figure 2). The incidence among groups is shown in Figure 3. In terms of the proportion of complete wound healing at the end of week 12, the nAg group demonstrated the highest proportion (81.8\%), followed by the $\mathrm{MH}$ group and the conventional group with $50 \%$ and $40 \%$, respectively. The overall complete healing was not significant among groups with $p$ value 0.267 . When the conventional group was used as a reference, the hazard ratio from Cox regression model for the $\mathrm{nAg}$ group was 2.179 [95\% confidence interval (CI) $0.669-7.906$ ] with $p$ value 0.196 . In other words, the subjects with DFU in the nAg group were estimated on the average $118 \%$ better healing potential at any particular time than those in the convention group. Similarly, the hazard ratio for the $\mathrm{MH}$ group was $1.208(95 \%$ CI 0.324-4.504) with reference to the conventional group $(p=0.778)$. The subjects with DFU in the $\mathrm{MH}$ group were estimated to have $21 \%$ better healing potential than those in the conventional group. However, the wide CI for both hazard ratios, which passed through the null effect of 1 , indicated that the differences were not statistically significant. 
TABLE 1: Comparison of baseline information on demographics and risk factors among groups.

\begin{tabular}{|c|c|c|c|c|c|}
\hline & $\begin{array}{c}\mathrm{nAg} \\
(n=11)\end{array}$ & $\begin{array}{c}\text { MH } \\
(n=10)\end{array}$ & $\begin{array}{c}\text { Conventional } \\
\quad(n=10)\end{array}$ & $p$ value & Significance \\
\hline \multicolumn{6}{|l|}{ Origin of participants } \\
\hline Hospital A & 9 & 7 & 8 & \multirow{3}{*}{$0.134^{\mathrm{a}}$} & \multirow{3}{*}{$\mathrm{NS}^{*}$} \\
\hline Hospital B & 2 & 3 & 0 & & \\
\hline GOPC & 0 & 0 & 2 & & \\
\hline \multicolumn{6}{|l|}{ Personal factors } \\
\hline \multicolumn{6}{|l|}{ Gender } \\
\hline M & 7 & 4 & 7 & \multirow{2}{*}{$0.433^{\mathrm{a}}$} & \multirow{2}{*}{ NS $*$} \\
\hline $\mathrm{F}$ & 4 & 6 & 3 & & \\
\hline $\begin{array}{l}\text { Age (years) } \\
{[\text { mean }(S D)]}\end{array}$ & $\begin{array}{c}63.36 \\
(11.31)\end{array}$ & $\begin{array}{l}65.60 \\
(11.42)\end{array}$ & $\begin{array}{c}66.1 \\
(12.31)\end{array}$ & $0.948^{\mathrm{b}}$ & NS* \\
\hline $\begin{array}{l}\text { Serum albumin level (mmol/ L) } \\
{[\text { mean }(\mathrm{SD})]}\end{array}$ & $\begin{array}{l}32.55 \\
(6.99)\end{array}$ & $\begin{array}{l}33.80 \\
(4.89)\end{array}$ & $\begin{array}{l}37.40 \\
(4.84)\end{array}$ & $0.147^{\mathrm{b}}$ & NS ${ }^{*}$ \\
\hline \multicolumn{6}{|l|}{ Ambulatory status } \\
\hline Ambulatory & 11 & 10 & 10 & NA & $\mathrm{NA}^{\mathfrak{E}}$ \\
\hline \multicolumn{6}{|l|}{ Disease factors } \\
\hline $\begin{array}{l}\text { Duration of diabetes (years) } \\
\text { [mean (SD)] }\end{array}$ & $\begin{array}{c}14.82 \\
(10.44)\end{array}$ & $\begin{array}{l}13.30 \\
(9.63)\end{array}$ & $\begin{array}{l}15.20 \\
(9.88)\end{array}$ & $0.921^{b}$ & $\mathrm{NS}^{*}$ \\
\hline $\begin{array}{l}\text { HbAlc level }(\mathrm{mmol} / \mathrm{L}) \\
{[\text { mean }(\mathrm{SD})]}\end{array}$ & $\begin{array}{c}8.27 \\
(1.32)\end{array}$ & $\begin{array}{c}8.30 \\
(2.26)\end{array}$ & $\begin{array}{c}7.59 \\
(0.99)\end{array}$ & $0.574^{\mathrm{b}}$ & NS* \\
\hline $\begin{array}{l}\text { Ankle brachial index (ABI) } \\
{[\text { mean }(\mathrm{SD})]}\end{array}$ & $\begin{array}{c}1.06 \\
(0.20)\end{array}$ & $\begin{array}{c}1.03 \\
(0.24)\end{array}$ & $\begin{array}{c}1.13 \\
(0.21)\end{array}$ & $0.944^{\mathrm{b}}$ & NS ${ }^{*}$ \\
\hline \multicolumn{6}{|l|}{ Heart disease } \\
\hline Yes & 4 & 5 & 6 & \multirow{2}{*}{$0.604^{\mathrm{a}}$} & \multirow{2}{*}{ NS ${ }^{*}$} \\
\hline No & 7 & 5 & 4 & & \\
\hline \multicolumn{6}{|l|}{ PAD } \\
\hline Yes & 1 & 0 & 1 & \multirow{2}{*}{$>0.9999^{\mathrm{a}}$} & \multirow{2}{*}{ NS ${ }^{*}$} \\
\hline No & 10 & 10 & 9 & & \\
\hline \multicolumn{6}{|l|}{ Local ulcer factors } \\
\hline \multicolumn{6}{|l|}{ Ulcer location on foot } \\
\hline Toe amputation & 7 & 2 & 2 & \multirow{8}{*}{$0.391^{\mathrm{a}}$} & \multirow{8}{*}{ NS* } \\
\hline Dorsum & 1 & 2 & 1 & & \\
\hline Plantar & 0 & 1 & 3 & & \\
\hline Plantar to dorsum & 1 & 0 & 0 & & \\
\hline Medial malleolus & 0 & 1 & 1 & & \\
\hline Anteromedial ankle & 1 & 2 & 0 & & \\
\hline Lateral malleolus & 1 & 1 & 2 & & \\
\hline Heel & 0 & 1 & 1 & & \\
\hline \multicolumn{6}{|l|}{ 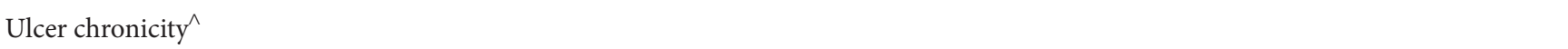 } \\
\hline Acute & 7 & 5 & 6 & \multirow{2}{*}{$0.901^{\mathrm{a}}$} & \multirow{2}{*}{ NS* } \\
\hline Chronic & 4 & 5 & 4 & & \\
\hline $\begin{array}{l}\text { Ulcer duration (weeks) } \\
\text { [mean (SD)] }\end{array}$ & $\begin{array}{l}11.45 \\
(6.67)\end{array}$ & $\begin{array}{l}12.80 \\
(10.54)\end{array}$ & $\begin{array}{l}14.70 \\
(8.12)\end{array}$ & $0.401^{\mathrm{b}}$ & NS* \\
\hline $\begin{array}{l}\text { Ulcer size }\left(\mathrm{cm}^{2}\right) \\
{[\text { mean }(\mathrm{SD})]}\end{array}$ & $\begin{array}{c}8.68 \\
(6.84)\end{array}$ & $\begin{array}{l}10.98 \\
(8.03)\end{array}$ & $\begin{array}{c}8.28 \\
(7.27)\end{array}$ & $0.495^{\mathrm{b}}$ & NS* \\
\hline \multicolumn{6}{|c|}{ University of Texas (UT) classification Ulcer grade (depth) } \\
\hline 0 & 0 & 1 & 1 & \multirow{4}{*}{$0.867^{\mathrm{a}}$} & \multirow{4}{*}{ NS* } \\
\hline 1 & 5 & 5 & 5 & & \\
\hline 2 & 6 & 4 & 4 & & \\
\hline 3 & 0 & 0 & 0 & & \\
\hline
\end{tabular}


TABLE 1: Continued.

\begin{tabular}{|c|c|c|c|c|c|}
\hline & $\begin{array}{c}\mathrm{nAg} \\
(n=11)\end{array}$ & $\begin{array}{c}\text { MH } \\
(n=10)\end{array}$ & $\begin{array}{l}\text { Conventional } \\
\quad(n=10)\end{array}$ & $p$ value & Significance \\
\hline $\begin{array}{l}\text { SWESS (score of 0-30) } \\
\text { [mean (SD)] }\end{array}$ & $\begin{array}{l}13.27 \\
(2.15)\end{array}$ & $\begin{array}{l}14.40 \\
(1.90)\end{array}$ & $\begin{array}{l}12.27 \\
(2.31)\end{array}$ & $0.195^{\mathrm{b}}$ & $\mathrm{NS}^{*}$ \\
\hline \multicolumn{6}{|l|}{ Clinical signs of infection } \\
\hline None & 7 & 3 & 6 & \multirow{3}{*}{$0.498^{\mathrm{a}}$} & \multirow{3}{*}{$\mathrm{NS}^{*}$} \\
\hline Mild & 3 & 6 & 3 & & \\
\hline Moderate & 1 & 1 & 1 & & \\
\hline
\end{tabular}

${ }^{\mathrm{a}}$ Fisher's exact test.

${ }^{\mathrm{b}}$ Kruskal-Wallis test.

${ }^{*}$ Not significant.

${ }^{£}$ Not available.

Significant $(p \leq 0.05)$.

${ }^{\wedge}$ Chronic wound was defined as wound duration $\geq 12$ weeks.

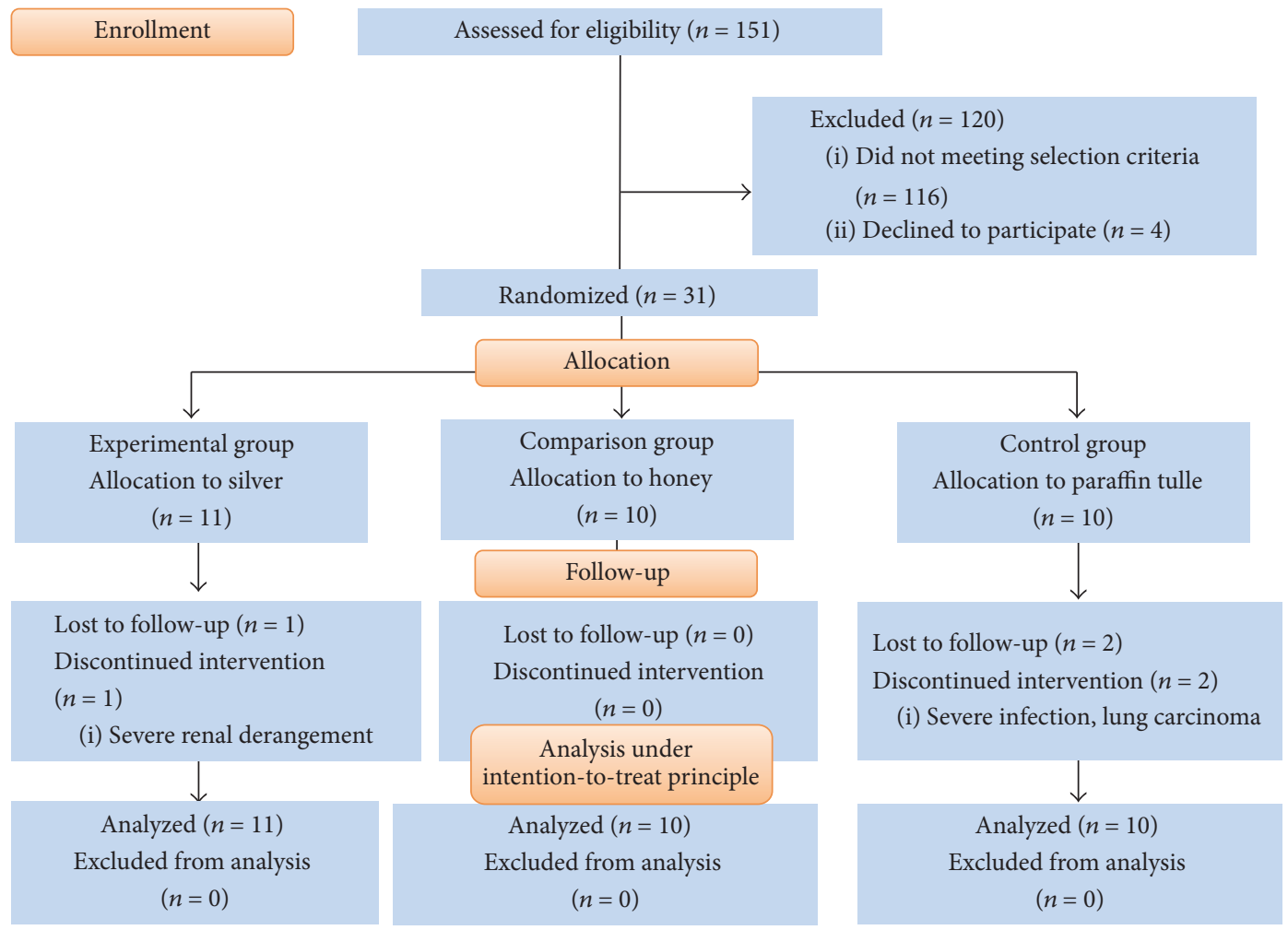

FIgURE 1: The CONSORT flow diagram.

3.2.2. Per-Protocol Analysis. One subject in the $\mathrm{nAg}$ group and two in the conventional groups were prematurely terminated and were excluded. The overall comparison among groups was not significant $(p=0.259)$. When comparing the $\mathrm{nAg}$ group and the $\mathrm{MH}$ group individually with conventional group, the $p$ values were 0.284 and 0.877 , respectively. Since similar results were obtained under the intention-totreat principle and per-protocol analysis, the progress of the subjects with premature termination was similar to that of other subjects in the study.

3.3. Ulcer Size Reduction Rate. The ulcer size reduction rate in terms of percentage of area reduction was examined among the three treatment groups. The percentage of area reduction in "week y" was (ulcer area of week 0 - ulcer area of week y)/ulcer area of week $0 \times 100 \%$. The mean ulcer size reduction rate in each group is shown in Figure 4.

The nAg group (97.45\%) had a higher reduction rate than the $\mathrm{MH}$ group (86.24\%) and the conventional group (76.91\%). The GEE was used to test whether any interaction effect among the groups would be found. The results showed that there was an interaction effect among the three groups with $p<0.0005$. This means that the ulcer size reduction rate in the nAg group was potentially higher than that in the $\mathrm{MH}$ group and the conventional group.

When the gradients of the three lines of the respective groups were compared with the conventional group set as the reference, the slopes of $\mathrm{nAg}$ and $\mathrm{MH}$ were 20.573 and 


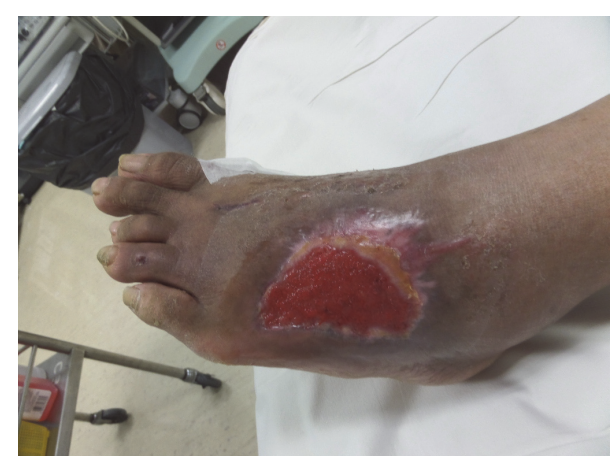

(a) Chronic DFU on week 1

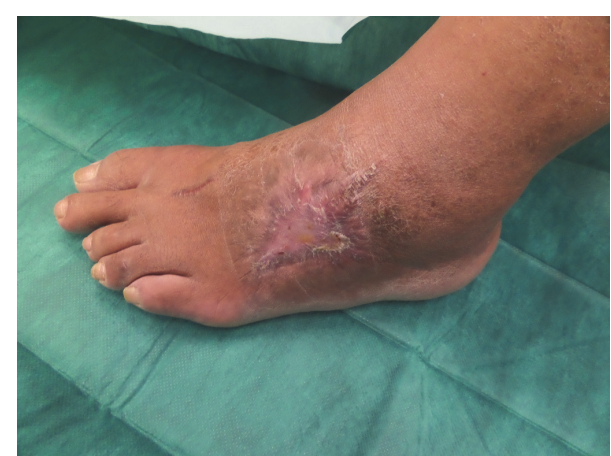

(b) Complete ulcer healing with smooth epithelial surface on week 10

Figure 2: Clinical photos for complete ulcer healing.

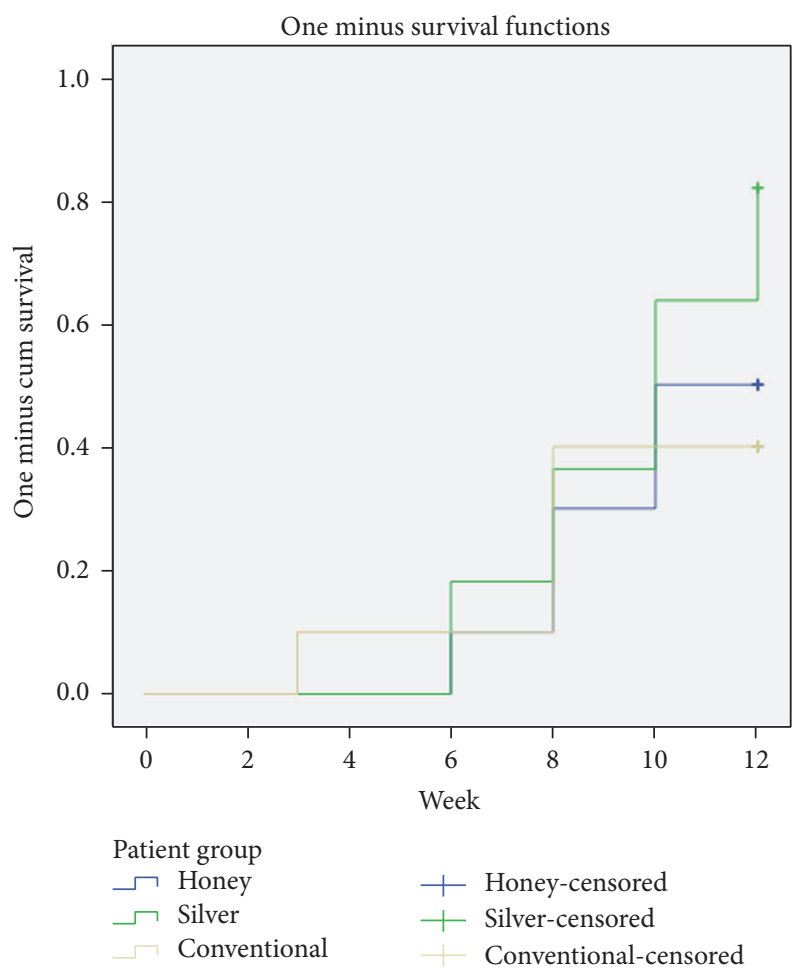

Figure 3: Cumulative healing incidence under the intention-totreat principle.

9.337, respectively. The positive values of the slopes in the $\mathrm{nAg}$ and $\mathrm{MH}$ groups imply an increasing trend when compared with the conventional group, with $p$ values of 0.011 and 0.311 , respectively. This indicated that the ulcer reduction rate of the nAg group was potentially higher than that of the conventional group. With the $\mathrm{MH}$ group acting as a reference, the $\mathrm{nAg}$ group had a potentially higher ulcer reduction rate than the MH group $(p<0.0005)$ (Table 2). As a whole, the $n$ Ag group had a higher ulcer size reduction rate than the $\mathrm{MH}$ group and the conventional group.

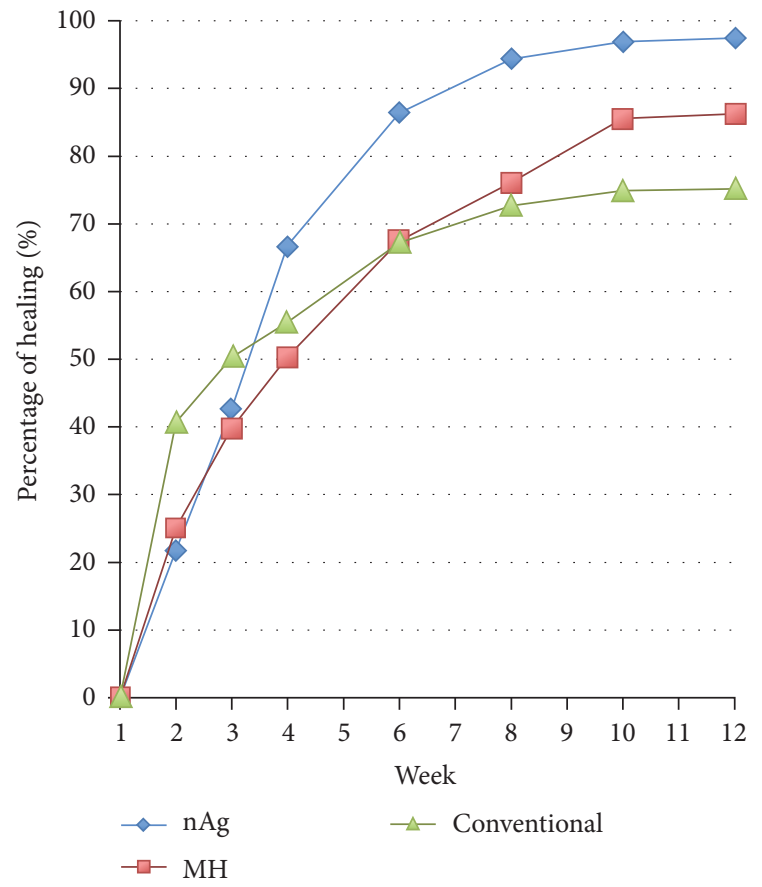

FIGURE 4: Ulcer size reduction rate in each group.

TABLE 2: Gradients of the $\mathrm{AAg}$ and $\mathrm{MH}$ groups on the change in ulcer size reduction.

\begin{tabular}{lccc}
\hline Group & Reference group & Gradient & $p$ value \\
\hline $\mathrm{nAg}$ & Conventional & 20.537 & $0.011^{*}$ \\
$\mathrm{MH}$ & Conventional & 9.337 & 0.311 \\
$\mathrm{nAg}$ & $\mathrm{MH}$ & 2.883 & $0.000^{*}$ \\
\hline
\end{tabular}

${ }^{*}$ Significant $(p \leq 0.05)$.

3.4. Bacteriology. In week 1 , the numbers of species of microorganism of the participants were $1.00(\mathrm{SD}=1.00), 1.56$ $(\mathrm{SD}=1.59)$, and $2.00(\mathrm{SD}=1.25)$ in the $\mathrm{n}$ g group, $\mathrm{MH}$ group, and conventional group, respectively. There was no significant difference in the number of species of microorganisms 


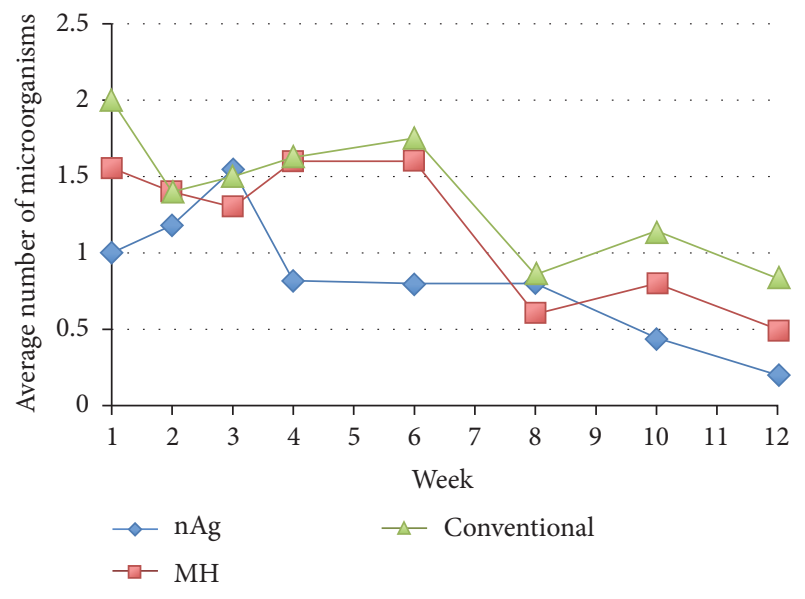

FIgURE 5: Average number of microorganisms among groups.

in week 1 among the three groups $(p=0.182)$. The numbers of species found among the groups all followed a decreasing trend over the 12-week study period. The decreasing trend in all three groups is shown in Figure 5. Examining the rate of decrease in the species of microorganisms among groups using the GEE showed that there was a significant difference in the overall interaction effect of "group and week" among groups, with $p$ value 0.003 .

When the interaction effect between groups was compared, the estimated marginal mean number of microorganisms in the nAg group was the lowest (0.86). The number of microorganisms in the conventional group was the highest (1.36) and that in the MH group was 1.17. The difference in means among the groups was not significant $(p=0.486)$. Although the nAg group did not show a significant decrease in bacteriology as compared with the MH group and the conventional group, it showed the greatest decreasing trend in the number of species of microorganisms.

The most common types of microorganisms in $\mathrm{nAg}$ group were Klebsiella and Pseudomonas aeruginosa. The average quantity of these two microorganisms was "heavy growth" by using the four-point scale of semiquantification surface swab count. On the other hand, the most common type of microorganism was Klebsiella in $\mathrm{MH}$ group. The corresponding quantification wound swab surface count was "heavy growth." In the conventional group, the most common type of microorganism was coagulase negative staphylococcus. The respective concentration on the wound bed was "moderate growth."

Besides, the presence of biofilm was another clinical parameter for the bacterial concentration on wound surface. There were eight observation points throughout the 12 weeks of the study period: weeks $1,2,3,4,6,8,10$, and 12 . At each time point, the presence or absence of biofilm was compared among groups using Fisher's exact test. The results are shown in Table 3 and found that there were no significant differences at each time point among groups throughout the 12-week study period.
3.5. Clinical Signs of Wound Infection. At each observation point, the presence or absence of clinical signs of infection was compared among groups using Fisher's exact test. The results are demonstrated in Table 4 , which shows that there were no significant differences at different observation points among the three groups throughout the 12-week study period.

3.6. Concentration Profile of Total Protein, MMP-9, TNF- $\alpha$, and $I L-1 \alpha$ in Wound Fluid. In week 1, the concentrations of total protein, MMP-9, TNF- $\alpha$, and IL- $1 \alpha$ in wound fluid had no significant differences among groups with $p$ value ranging between $0.804,0.053,0.209$, and 0.184 , respectively.

The change in mean total protein concentration was analyzed among the groups. There was an up and down trend in the $\mathrm{nAg}$ and $\mathrm{MH}$ groups. Total protein decreased steadily in the conventional group (Figure 6). When examining changes in the concentration among groups over the first 4 weeks, the GEE indicated that there was no significant difference in the entire overall "week and group" effect, with $p$ value 0.081 , nor was there any interaction effect among ( $p=0.782)$ or within groups $(p=0.992)$ over time.

The change in mean MMP-9 concentration among the groups over the first 4 weeks was considerable as shown in Figure 7. An upward trend in the $\mathrm{MH}$ group was noted while the $\mathrm{nAg}$ and conventional groups reported a nonlinear trend.

Using GEE analysis model, an overall interaction effect among the groups was observed with $p$ value $<0.0005$. When the gradients of the three lines of the respective groups were compared with the conventional group set as the reference, the slopes of $\mathrm{nAg}$ and $\mathrm{MH}$ were 1.263 and 1.507 , respectively. The positive values of the slope in the $\mathrm{nAg}$ and $\mathrm{MH}$ groups implied an increasing trend when compared with the conventional group, with $p$ values of 0.027 and $<0.0005$, respectively. This showed that there was a significant increasing trend between the $\mathrm{nAg} / \mathrm{MH}$ groups and the conventional groups. When the $\mathrm{MH}$ group was taken as the reference, there was no significant difference between it and the nAg group ( $p=0.089)$ (Table 5).

When the ratio of MMP-9 and total protein was compared among groups over the first 4 weeks, there was still no obvious trend found in each group (Figure 8). The GEE model showed that there was no overall interaction effect among groups over time $(p=0.753)$.

Similar to MMP-9, the change in mean TNF- $\alpha$ concentration in wound fluid was extensive within each group over the 4-week period. As shown in Figure 9, TNF- $\alpha$ in the $\mathrm{MH}$ group decreased whereas that in the $\mathrm{nAg}$ group, on the contrary, increased. By contrast, TNF- $\alpha$ in the conventional group remained more or less constant.

On interaction effect examination, there was no overall "week and group" effect $(p=0.061)$. For IL- $1 \alpha$, the variations in level within the groups were high. The trends in the change in mean IL- $1 \alpha$ concentration differed in the three groups, the tendency of which was found similar in the case of MMP9 and TNF- $\alpha$ (Figure 10). By using the GEE model to assess the interaction effect, no overall "week and group" interaction effect was found among the groups with $p$ value 0.177 . 
TABLE 3: The presence of biofilm at different observation points among the three groups.

\begin{tabular}{|c|c|c|c|c|c|c|}
\hline \multirow[b]{2}{*}{ Week } & \multirow[b]{2}{*}{ Biofilm } & \multicolumn{3}{|c|}{ Treatment group } & \multirow[b]{2}{*}{$p$ value } & \multirow[b]{2}{*}{ Significance } \\
\hline & & $\begin{array}{c}\mathrm{nAg} \\
(n=11)\end{array}$ & $\begin{array}{c}\text { MH } \\
(n=10)\end{array}$ & $\begin{array}{c}\text { Conventional } \\
\quad(n=10)\end{array}$ & & \\
\hline \multirow{3}{*}{1} & Yes & 6 & 6 & 3 & \multirow{3}{*}{0.439} & \multirow{3}{*}{$\mathrm{NS}^{\mathrm{a}}$} \\
\hline & No & 5 & 4 & 7 & & \\
\hline & $\mathrm{NA}^{\mathrm{b}}$ & 0 & 0 & 0 & & \\
\hline \multirow{3}{*}{2} & Yes & 6 & 6 & 6 & \multirow{3}{*}{$>0.9999$} & \multirow{3}{*}{$\mathrm{NS}^{\mathrm{a}}$} \\
\hline & No & 5 & 4 & 4 & & \\
\hline & $\mathrm{NA}^{\mathrm{b}}$ & 0 & 0 & 0 & & \\
\hline \multirow{3}{*}{3} & Yes & 9 & 7 & 5 & \multirow{3}{*}{0.477} & \multirow{3}{*}{$\mathrm{NS}^{\mathrm{a}}$} \\
\hline & No & 2 & 3 & 4 & & \\
\hline & $\mathrm{NA}^{\mathrm{b}}$ & 0 & 0 & 1 & & \\
\hline \multirow{3}{*}{4} & Yes & 7 & 7 & 5 & \multirow{3}{*}{0.828} & \multirow{3}{*}{$\mathrm{NS}^{\mathrm{a}}$} \\
\hline & No & 4 & 3 & 4 & & \\
\hline & $\mathrm{NA}^{\mathrm{b}}$ & 0 & 0 & 1 & & \\
\hline \multirow{3}{*}{6} & Yes & 4 & 4 & 3 & \multirow{3}{*}{$>0.9999$} & \multirow{3}{*}{$\mathrm{NS}^{\mathrm{a}}$} \\
\hline & No & 5 & 5 & 6 & & \\
\hline & $\mathrm{NA}^{\mathrm{b}}$ & 2 & 1 & 1 & & \\
\hline \multirow{3}{*}{8} & Yes & 2 & 3 & 2 & \multirow{3}{*}{$>0.9999$} & \multirow{3}{*}{$\mathrm{NS}^{\mathrm{a}}$} \\
\hline & No & 5 & 4 & 4 & & \\
\hline & $\mathrm{NA}^{\mathrm{b}}$ & 4 & 3 & 4 & & \\
\hline \multirow{3}{*}{10} & Yes & 2 & 2 & 2 & \multirow{3}{*}{0.879} & \multirow{3}{*}{$\mathrm{NS}^{\mathrm{a}}$} \\
\hline & No & 2 & 3 & 4 & & \\
\hline & $\mathrm{NA}^{\mathrm{b}}$ & 7 & 5 & 4 & & \\
\hline \multirow{3}{*}{12} & Yes & 2 & 3 & 3 & \multirow{3}{*}{0.271} & \multirow{3}{*}{$\mathrm{NS}^{\mathrm{a}}$} \\
\hline & No & 0 & 2 & 3 & & \\
\hline & $\mathrm{NA}^{\mathrm{b}}$ & 9 & 5 & 4 & & \\
\hline
\end{tabular}

$\mathrm{NS}^{\mathrm{a}}$ : not significant.

$\mathrm{NA}^{\mathrm{b}}$ : not available (DFU healed).

3.7. Use of Antibiotics. The use of antibiotics was a confounder in affecting changes in bacteriology and the clinical signs of wound infection on DFU. Hence, it would affect ulcer healing. Only one participant with severe wound infection in the control group needed intravenous antibiotics during the study period. He was discontinued with the topical intervention, prematurely terminated from the study, and admitted to the hospital. There were totally 30 episodes of participants taking oral antibiotics in the study period: 12 in the $\mathrm{nAg}$ group, 11 in the $\mathrm{MH}$ group, and 7 in the conventional group. In each clinic visit, one participant taking oral antibiotics was counted as one episode. Among these episodes, around half involved participants continuing taking antibiotics upon discharge from hospital. Only five episodes involved the participants commencing oral antibiotics during the study period. Every single time point was compared among groups using Fisher's exact test. There were no significant differences among the three groups. The $p$ values were between 0.174 and $>0.9999$. The result revealed that there were no significant differences in the distribution of antibiotic use among the three groups throughout the 12 -week study period. This implies that the confounder "use of oral antibiotics" did not affect the comparison of ulcer healing among groups.

3.8. Adverse Event. In addition, there were six episodes of adverse events occurring during the study period. Four were in the conventional group, and there was one in each of the $\mathrm{MH}$ and the nAg groups. Among all the adverse events, four of them were prescribed antibiotics (Table 6). By using the Chi-square, there was no significant difference in the adverse events among groups $(p=0.54)$. The details of the adverse events and interventions were shown in Table 6.

3.9. Cost-Effectiveness Analysis. The prices of $\mathrm{nAg}, \mathrm{MH}$, and paraffin tulle dressings varied in Hong Kong. The prices of nAg dressing (Acticoat absorbent), MH dressing (Manuka ${ }^{\mathrm{TM}}$ honey gel sheet), and paraffin tulle (Jelonet) of $10 \times 12.5 \mathrm{~cm}$ were (in Hong Kong dollars) \$158.00, \$225.00, and \$13.75 per piece, respectively. The prices of Acticoat absorbent and Manuka honey gel sheet were 11.5 times and 16.4 times higher than that of paraffin tulle dressing. When we compared 
TABLE 4: Clinical signs of wound infection at different observation points among the three groups.

\begin{tabular}{|c|c|c|c|c|c|c|}
\hline Week & $\begin{array}{l}\text { Infection } \\
\text { status }\end{array}$ & $\begin{array}{c}\mathrm{nAg} \\
(n=11)\end{array}$ & $\begin{array}{c}\text { MH } \\
(n=10)\end{array}$ & $\begin{array}{c}\text { Conventional } \\
\quad(n=10)\end{array}$ & $p$ value & Significance \\
\hline \multirow{3}{*}{1} & Yes & 7 & 3 & 6 & \multirow{3}{*}{0.296} & \multirow{3}{*}{$\mathrm{NS}^{\mathrm{a}}$} \\
\hline & No & 4 & 7 & 4 & & \\
\hline & $\mathrm{NA}^{\mathrm{b}}$ & 0 & 0 & 0 & & \\
\hline \multirow{3}{*}{2} & Yes & 10 & 6 & 9 & \multirow{3}{*}{0.262} & \multirow{3}{*}{$\mathrm{NS}^{\mathrm{a}}$} \\
\hline & No & 1 & 4 & 1 & & \\
\hline & $\mathrm{NA}^{\mathrm{b}}$ & 0 & 0 & 0 & & \\
\hline \multirow{3}{*}{3} & Yes & 10 & 9 & 8 & \multirow{3}{*}{0.825} & \multirow{3}{*}{$\mathrm{NS}^{\mathrm{a}}$} \\
\hline & No & 1 & 1 & 1 & & \\
\hline & $\mathrm{NA}^{\mathrm{b}}$ & 0 & 0 & 1 & & \\
\hline \multirow{3}{*}{4} & Yes & 10 & 8 & 9 & \multirow{3}{*}{0.825} & \multirow{3}{*}{$\mathrm{NS}^{\mathrm{a}}$} \\
\hline & No & 1 & 2 & 0 & & \\
\hline & $\mathrm{NA}^{\mathrm{b}}$ & 0 & 0 & 1 & & \\
\hline \multirow{3}{*}{6} & Yes & 8 & 8 & 9 & \multirow{3}{*}{$>0.9999$} & \multirow{3}{*}{$\mathrm{NS}^{\mathrm{a}}$} \\
\hline & No & 1 & 1 & 0 & & \\
\hline & $\mathrm{NA}^{\mathrm{b}}$ & 2 & 1 & 1 & & \\
\hline \multirow{3}{*}{8} & Yes & 6 & 7 & 6 & \multirow{3}{*}{$>0.9999$} & \multirow{3}{*}{$\mathrm{NS}^{\mathrm{a}}$} \\
\hline & No & 1 & 0 & 0 & & \\
\hline & $\mathrm{NA}^{\mathrm{b}}$ & 4 & 3 & 4 & & \\
\hline \multirow{3}{*}{10} & Yes & 3 & 5 & 6 & \multirow{3}{*}{0.496} & \multirow{3}{*}{$\mathrm{NS}^{\mathrm{a}}$} \\
\hline & No & 1 & 0 & 0 & & \\
\hline & $\mathrm{NA}^{\mathrm{b}}$ & 7 & 5 & 4 & & \\
\hline \multirow{3}{*}{12} & Yes & 2 & 5 & 4 & \multirow{3}{*}{0.150} & \multirow{3}{*}{$\mathrm{NS}^{\mathrm{a}}$} \\
\hline & No & 0 & 0 & 0 & & \\
\hline & $\mathrm{NA}^{\mathrm{b}}$ & 9 & 5 & 4 & & \\
\hline
\end{tabular}

$\mathrm{NS}^{\mathrm{a}}$ : not significant.

$\mathrm{NA}^{\mathrm{b}}$ : not available (DFU healed).

the ulcer size reduction rate in week 12, the nAg group was $97.25 \%$. The $\mathrm{MH}$ group and the conventional group were $86.24 \%$ and $76.91 \%$, respectively. However, the clinical effectiveness of Acticoat absorbent and that of Manuka honey gel sheet were only 1.3 times and 1.1 times better than that of paraffin tulle dressing. In this study, all of the participants were outpatients who received daily dressing. The costs for dressing by community nurse and O\&T nurse clinic attendances were the same. Therefore, if specialized nursing care including showering before dressing and debridement was performed, paraffin tulle dressing was recommended from the point of view of cost-effectiveness according to the preliminary data. Importantly, further solid recommendation can be made until more subjects are recruited in the future study.

\section{Discussion}

4.1. Cumulative Healing Incidence. To the best of our knowledge, this is not only the first pilot randomized controlled trial to compare the effect of $\mathrm{nAg}$ dressing, $\mathrm{MH}$ dressing, and conventional dressing on DFU, but also the first attempt to examine the changes in MMP and cytokines levels in wound fluid among different treatment groups. In this pilot study, the proportion of healing in the nAg group was higher than that in the $\mathrm{MH}$ group and the conventional group for more than $30 \%$ at the end of the 12 -week study period. Yet, the difference did not reach statistical significance. From the published randomized controlled trials, there was no direct comparison of $\mathrm{nAg}$ against $\mathrm{MH}$ on DFU. Fries et al. [21] compared the effectiveness of $\mathrm{nAg}$ dressing against plain gauze in the postdebridement of military wounds. From the figures reported in the paper, it was found that the days of wound healing in the nAg group (about 21 days) were slightly longer than those of the control group (about 19 days) although the result had no significant difference.

The findings from Fries et al.s study did not support the present study. The reason for the differences in the present study and Fries et al's study may be due to the differences in wound types. In the present study, most of the ulcers were chronic or acute on chronic wounds, while the ulcers in Fries et al.s study were acute wounds. This may be the difference in the degree of inflammation. The DFU involved in the present study had mild to moderate infection. All the DFU had 1 to 3 


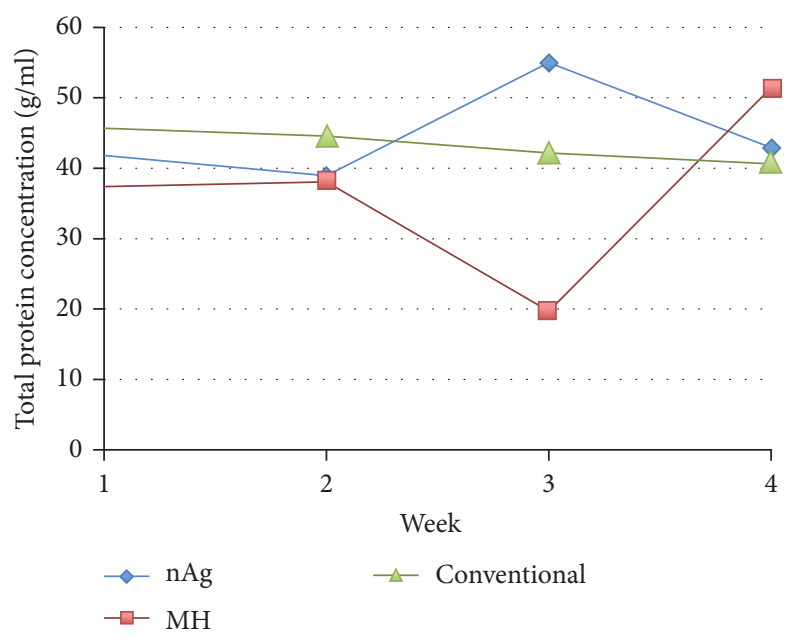

FIGURE 6: Mean concentration profile of total protein among the three groups.

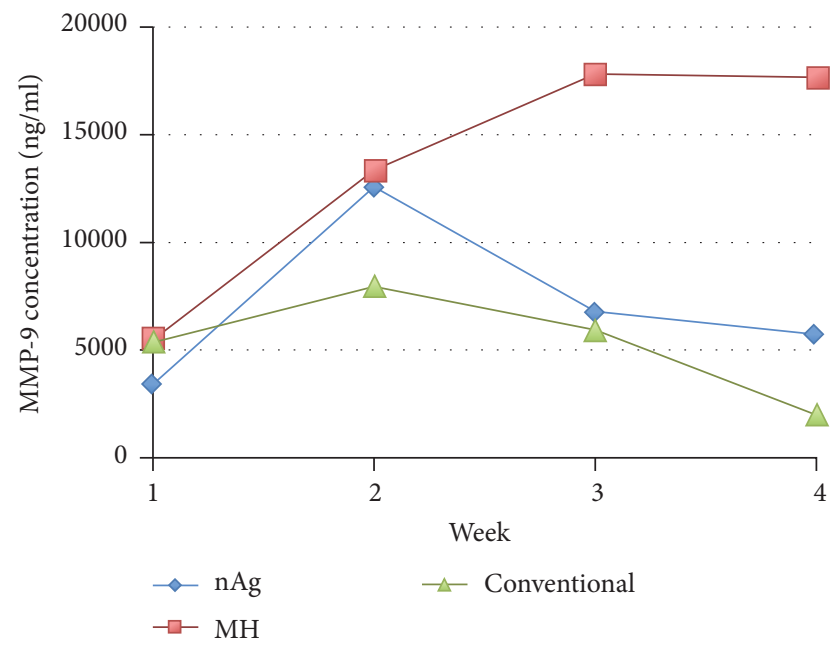

FIGURE 7: Mean concentration profile of MMP-9 among the three groups.

TABLE 5: Gradients of the nAg and $\mathrm{MH}$ groups on the change of MMP-9 concentration.

\begin{tabular}{lccc}
\hline Group & Reference group & Gradient & $p$ value \\
\hline $\mathrm{nAg}$ & Conventional & 1.263 & $0.027^{*}$ \\
$\mathrm{MH}$ & Conventional & 1.507 & $0.000^{*}$ \\
$\mathrm{nAg}$ & $\mathrm{MH}$ & -0.427 & 0.098 \\
\hline
\end{tabular}

${ }^{*}$ Significant $(p \leq 0.05)$.

types of microorganism cultured in the first week. However, in Fries et al.'s study, there were $58 \%$ and $37 \%$ yielded negative culture of microorganism on the intervention and control groups, respectively. The low bacterial loading in Fries et al's study might decrease the efficiency of antibacterial effect in nAg dressing.

In addition, Gottrup et al. [22] reported on using collagen silver against standard care in DFU. They found that $52 \%$ were healed in the collagen silver group while $31 \%$ were healed

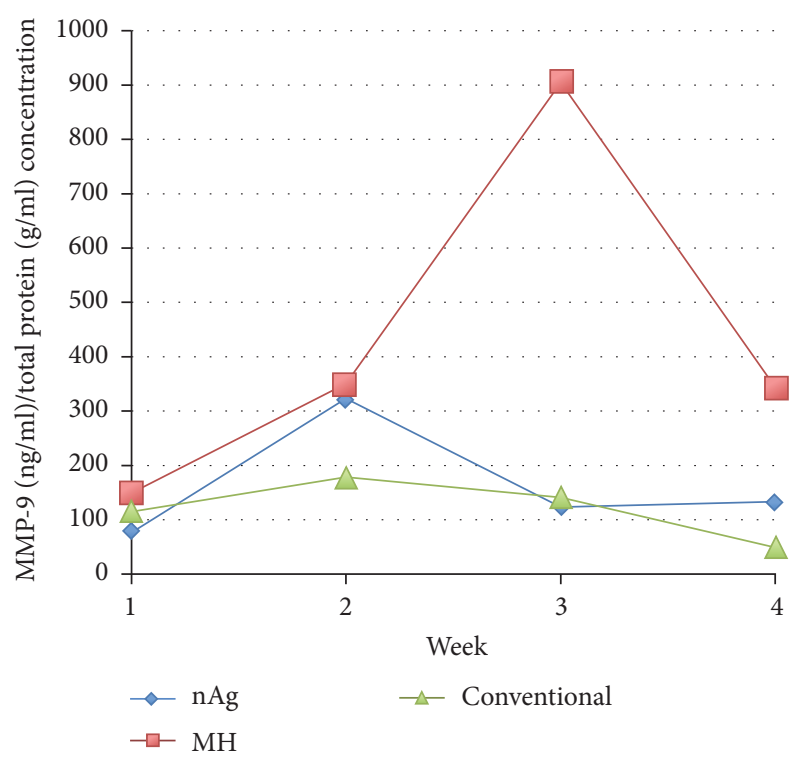

FIGURE 8: Mean concentration profile of the ratio of MMP-9 and total protein among the three groups.

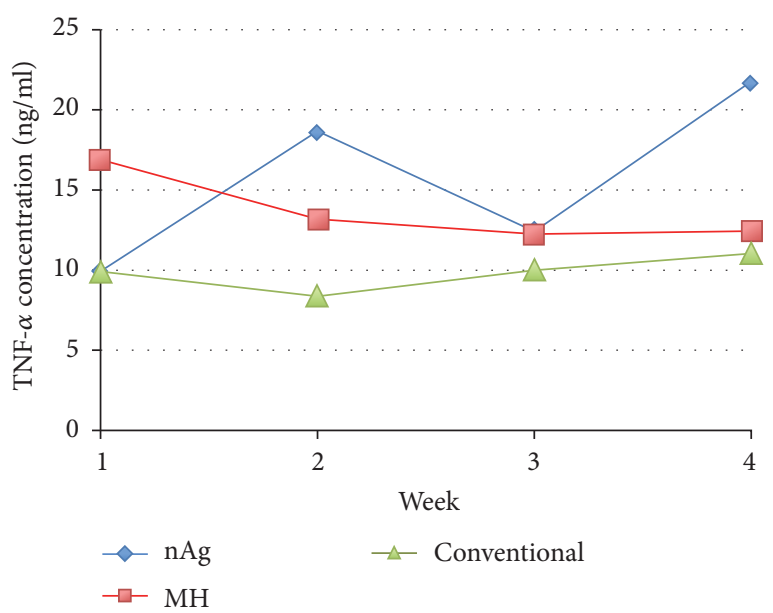

FIGURE 9: Mean concentration profile of TNF- $\alpha$ among the three groups.

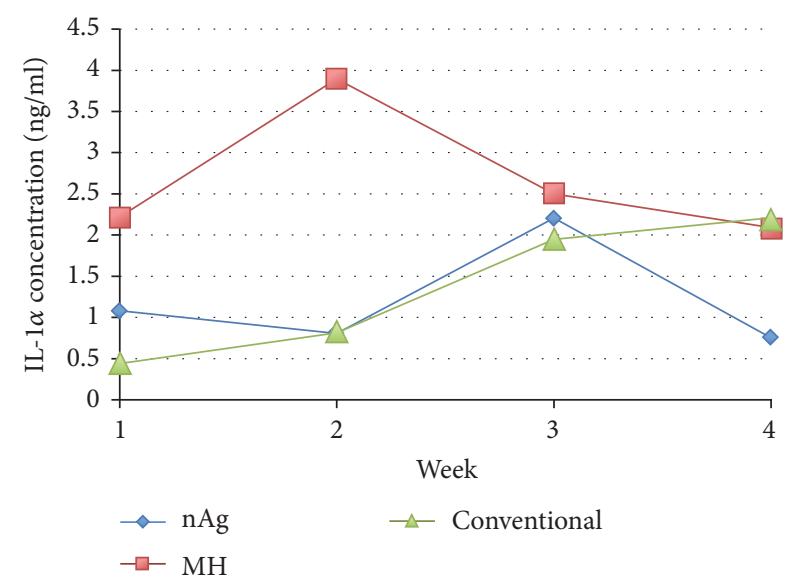

FIgURE 10: Mean concentration profile of IL-1 $\alpha$ among the three groups. 
TABLE 6: Adverse event and interventions.

\begin{tabular}{lcc}
\hline Group & Adverse event & Intervention \\
\hline $\mathrm{nAg}$ & Calf swelling & Oral antibiotics \\
\hline $\mathrm{MH}$ & Generalized blister & Oral steroid and antibiotics prescribed in the family clinic \\
\hline & Lung carcinoma & Referred to oncology department and patient discontinued from the study \\
& Chest infection & Oral antibiotics \\
Conventional & Blisters near the ulcer due to & Activity restriction \\
& friction on walking & Admission for intravenous antibiotics and patient discontinued from the study \\
\hline
\end{tabular}

in the control group. However, the topical dressing in the treatment group contained collagen and silver. Both collagen and silver contributed to the DFU healing simultaneously. Although our present findings were similar to Gottrup et al.'s study, it was impossible to identify the single effect of silver. The study results from the two studies made it difficult to perform a direct comparison.

Kamaratos et al. [17] compared the $\mathrm{MH}$ and standard care on DFU. The result was similar to our study. They found that $97 \%$ were healed in $\mathrm{MH}$ group and $90 \%$ under conventional care. There was no noticeable difference between the groups. The proportion of healing in both groups in their study was higher than that of the present study. This can be explained by the fact that they excluded subjects with $A B I$ $<0.9$ so the ulcers had a better blood perfusion, which may result in higher proportion of complete wound healing. The selected ulcers were less severe than our study's. Al Saeed [16] performed another comparison study between $\mathrm{MH}$ dressing and conventional dressing on DFU. The author illustrated that $\mathrm{MH}$ was a superior topical intervention to the conventional dressing. The proportion of healing in $\mathrm{MH}$ group and control group was $61.3 \%$ versus $11.5 \%$ at six-week intervals. The proportion of healing in $\mathrm{Al}$ Saeed's study was much higher than that reported in the present study. It might be due to the reason that surgical interventions, including toe amputation, were performed to all participants during the study period. This may facilitate the ulcer healing in Al Saeed's study.

4.2. Ulcer Size Reduction Rate. In the present study, the percentage of reduction in ulcer size was potentially higher in the $\mathrm{nAg}$ group when compared with the $\mathrm{MH}$ group and the conventional dressing group at the end of week 12. Ulcer size reduction is a sign of ulcer healing. It was a common study outcome to indicate wound healing in wound care research. In the present study, almost all the DFUs had mild to moderate wound infection in the 1st week of the study, so the potency of antibacterial effect became important for healing in this study. Kwakman et al. [13] found that the antibacterial effect of $\mathrm{MH}$ was onset slower than $\mathrm{nAg}$. On the other hand, the exact mechanisms of the anti-inflammatory effect of $\mathrm{MH}$ and $\mathrm{nAg}$ were not entirely clear and their relative potency was unknown. The conventional dressing had neither antibacterial nor anti-inflammatory effect. That was the reason for the result in this study that the $\mathrm{nAg}$ dressing was superior to the $\mathrm{MH}$ dressing and the conventional dressing in ulcer size reduction.

Only a few studies ever compared the ulcer size reduction rate between groups directly. The strength of this pilot study was the use of repeated measures to compare the DFU size reduction rate longitudinally among groups. Miller et al. [23] compared the effectiveness of $\mathrm{nAg}$ on venous ulcer and had similar findings to ours. They revealed that the proportion of healing between the nAg group and the cadexomer iodine group was not statistically different within 12 weeks of time but the wound healing rate in the first two weeks was faster in the nAg group on larger, older, and more exuding wounds by using the linear mixed model for comparison. This may be due to the fact that large wounds with more exudate usually have higher bacterial concentration. For this type of wound, the antibacterial action of $\mathrm{nAg}$ became more important and significant difference was found in this type of wound.

Regarding the small sample size in this study, the preliminary findings could not draw a solid conclusion but it served as a useful reference as a pilot. The preliminary data suggested that the $\mathrm{nAg}$ dressing was potentially better than the MH and conventional dressings in DFU healing in terms of wound size reduction rate. It also revealed that the complete wound healing was also potentially higher in the $\mathrm{nAg}$ dressing than the $\mathrm{MH}$ and conventional dressings despite the fact that it was not significant. This may be because the sample size was not large enough to differentiate the differences in the cumulative healing incidence but it was sufficient to work out the ulcer size reduction rate among groups. Importantly, the soap cleansing and repeated sharp debridement were given to all participants and this may further reduce the detectable differences among groups. It was because soap cleansing and sharp debridement removed nonviable tissues, debris, and biofilms [24], which could help in ulcer healing.

4.3. Changes of Bacteriology. Examining the changes in bacteriology should include the types of species of microorganism and the corresponding quantity. Due to the small sample size in this pilot study, only the types of species of microorganism were included for analysis. The decrease in the number of species of microorganism was not different in the three groups but the estimated marginal mean indicated the least bacteria in the $\mathrm{nAg}$ dressing group followed by the $\mathrm{MH}$ and the conventional dressing groups. Although $\mathrm{MH}$ has MGO [12] that is responsible for antibacterial function, 
the hyperosmolarity [11] is probably the greatest effect that is bacteriostatic rather than bactericidal. In addition, the antibacterial effect of $\mathrm{nAg}$ is much faster than that of $\mathrm{MH}$ [13]. These are the possible reasons for the change in bacteriology in descending order: $\mathrm{nAg}$ dressing, $\mathrm{MH}$ dressing, and conventional dressing. However, the specialized nursing intervention of cleansing the ulcer by soap and water before dressing in all participants would reduce the bacteria on the ulcer surface by the surfactant effect. This may further decrease the differences of bacteriology among groups.

This result was supported by those reported in the in vitro and clinical studies. In the in vitro study, Bradshaw [25] found that there was no significant difference between nAg and $\mathrm{MH}$ dressings on common wound pathogen including $E$. coli, S. aureus, and P. aeruginosa. Kamaratos et al.'s [17] clinical study revealed that there was no significant difference in presence of sterile DFUs between their $\mathrm{MH}$ and conventional dressing groups with 63 patients. However, $78.13 \%$ of ulcers became sterile in the $\mathrm{MH}$ dressing group versus $35.5 \%$ in the conventional dressing group during the first week. The corresponding percentages for weeks 2 , 4, and 6 were $15.62 \%$, $38.7 \%$, and $6.25 \%$ in the $\mathrm{MH}$ group and $12.9 \%, 0 \%$, and $12.9 \%$ for weeks 2, 4, and 6 in the conventional dressing group. As a whole, the present study and the previous studies showed that the participants with $\mathrm{MH}$ dressing or $\mathrm{nAg}$ dressing had an observable lower number in bacteria but did not reach the statistical significance.

Throughout the study period, there was no significant difference in the presence of biofilm among the three groups from week 1 to week 12 even though $\mathrm{nAg}$ dressing and $\mathrm{MH}$ dressings had the antibacterial effect. The possible reason for the insignificant result was probably due to the effect on debridement on every clinical visit since debridement was the most simple and effective method for biofilm removal [26].

4.4. Clinical Signs of Wound Infection. In the present study, there was no significant difference in the signs of wound infection among the three groups from week 1 to week 12 although the nAg and $\mathrm{MH}$ dressings had the antibacterial effects. As a whole, the percentage of clinical signs of wound infection was also not significant among groups over the 12 weeks. The result from our study was not supported by the published literature. Gottrup et al. [22] compared the silver collagen against the control group with the local standard dressings on DFU and found that the silver collagen group had no signs of infection, while the control group had $31 \%$ of infection. Al Saeed [16] compared the effects of $\mathrm{MH}$ dressing versus tulle gras on DFU. It showed that $\mathrm{MH}$ dressing combined with surgery had an obvious shorter time to eradicate infection than the control group with conventional dressing combined with surgery.

The present preliminary result on clinical signs of wound infection was different from these previous studies. The possible reasons for this difference are as follows. Firstly, specialized nursing education was given to each of the participants. They were required to perform showering with running water before dressing. The specialized nursing intervention on debridement could also remove the biofilm and the nonviable tissues. These procedures could further decrease the bacterial concentration on the wound bed in the three groups. Secondly, regardless of the wound types, the possible reason was the small effect size of the antibacterial effect between the $\mathrm{nAg} / \mathrm{MH}$ dressing, $\mathrm{nAg} /$ conventional dressing, and $\mathrm{MH} /$ conventional dressing so that the small sample size could not detect the difference statistically.

4.5. The Change in Concentration of MMP-9 and Ulcer Healing. As shown in the result, the trend of MMP-9 concentration in the $\mathrm{nAg}, \mathrm{MH}$, and conventional dressing groups fluctuated. The trend of MMP-9 concentration in the three groups was not along with DFU healing in the 4-week interval. The gradient analysis indicated that the increasing rate of MMP- 9 concentration in the $\mathrm{nAg}$ and $\mathrm{MH}$ dressing groups was potentially higher than the conventional group. In combination with these results, it implied that the nAg and $\mathrm{MH}$ dressing groups had poor healing as compared with the conventional dressing group because the activities of MMP-9 declined when wound started to heal [27, 28].

However, as reported above, the nAg group had better ulcer healing in terms of higher reduction rate of ulcer size than the conventional dressing group. Therefore, it was found in this study that the change of concentration level of MMP-9 did not align with the reduction rate of DFU size, which was different from the results of the previous studies. According to the published literature, it was found that the change in concentration of MMP-9 was negatively correlated with the wound healing status $[27,28]$. The concentration of MMP-9 declined in wound healing in progress.

Indeed, MMP-9 is a well-recognized MMP that plays an important role in normal healing [25] and appears to be the major protease responsible for matrix degradation in chronic wound fluid [29]. MMP-9 is produced by a number of inflammatory cells, including neutrophil, macrophage, and monocyte. In the proliferative phase of wound healing, their activities decline [30]. This is the reason why MMP-9 decreases in the normal wound healing process.

The possible reasons for the difference between the present pilot study and the previous studies were that some of the DFUs of certain participants in the present study were in a rather acute stage when compared with the above studies and had surgeries prior to the recruitment in the present study. Theoretically, the debridement procedure in the operation theatre would cause wound bleeding and turn the ulcer into an acute stage. In addition, compared with the DFUs in Cullen et al.s study [31], which were noninfected, the DFUs in the present study had different degrees of infection. The bacteria toxin recruited the inflammatory cells for the production of proteases [27]. It would increase the proteases level and the levels were not downregulated during the inflammatory and infected stage regardless of the use of topical dressing material. Therefore, in our study, the concentration of MMP-9 in both $\mathrm{nAg}$ and $\mathrm{MH}$ dressing groups did not decrease.

4.6. The Change in Concentration of Cytokines TNF- $\alpha$ and IL$1 \alpha$ and Ulcer Healing. It was found in the present study that the trends of cytokines TNF- $\alpha$ and IL- $1 \alpha$ concentrations in the three groups were up and down in the 4-week interval. 
There was no obvious increasing or decreasing trend. This tendency was the same as the trend of total protein and MMP9 concentration. The interaction effect was not statistically significant. Interestingly, TNF- $\alpha$ is a powerful inducer of MMP-9 [32]. From the study result, we found that the mean concentration of MMP-9 was higher in the MH group than the $\mathrm{nAg}$ group. However, the concentration of TNF- $\alpha$ was vice versa between both groups. The possible explanation may be due to other unknown factors in affecting the relationship between MMP-9 and TNF- $\alpha$. Importantly, it needs to be further explored in the future studies.

Indeed, both TNF- $\alpha$ and IL- 1 are mainly secreted by neutrophils and macrophages. TNF- $\alpha$ helps in collagen synthesis, while IL-1 is used to recruit fibroblasts and keratinocytes and in collagen synthesis [33]. Macrophages and neutrophils are the dominant cells in the inflammatory stage of wound healing and their activities are minimized in the proliferative stage [34]. As a consequence, the levels of IL- 1 and TNF- $\alpha$ decrease as the wound starts to heal. Trengove et al. [35] studied the mitogenic activity of healing and nonhealing ulcer. They found that the levels of proinflammatory cytokines TNF$\alpha$ and IL-1 were downregulated during the healing process. Yussof et al. [33] suggested that cytokines including TNF- $\alpha$ and IL-1 hold the most potential to predict wound healing.

4.7. Possible Reasons for the Inconsistency between the Results of Ulcer Healing and the Change in Concentration of Biomarkers. We could speculate several possible reasons for the inconsistent findings between the laboratory and clinical observations. Firstly, most of the previous researches in this area mainly focused on the chronic nonhealing and noninfected wounds. Some even compared the acute wound fluid with the chronic wound fluid $[27,35,36]$. One of the studies focused on the noninfected ulcer [31] or chronic ulcer only [30]. In the present pilot study, chronicity of ulcers varied. It is noteworthy that all of the DFUs in this study were in the healing stage during the study period.

Secondly, as mentioned before, soap and water cleansing before dressing would decrease the bacterial loading and it would affect the MMPs and cytokines levels since the bacteria were an important factor to recruit the inflammatory cells for secreting these biomarkers. Thirdly, serial sharp debridement was performed in every follow-up during the study period. There were different degrees of bleeding after the debridement procedure. Apart from debridement, the avascular tissue was stimulated to bleed because most of the ulcers involved in this study had tendon and fascia exposed. As a result, acute minor trauma was performed periodically during the study period. The related interventions produced new wounds in order to attract neutrophils and fibroblasts to migrate to the local area. The cells were being stimulated to produce MMPs and cytokines [33]. Although the above interventions produced counterbalance effect, these interventions might be the important cofounders affecting the levels of MMPs and cytokines.

Another possible reason is that these studies categorized the chronic wounds into healing and nonhealing groups and tested the differences of the biomarkers concentration between groups [37-39]. However, in the present study, the concentration of the biomarkers in wound fluid was the laboratory outcome while complete wound healing and ulcer size reduction were the clinical outcomes. The two types of outcomes were triangulated to evaluate the effectiveness of the $\mathrm{nAg}$ dressing against the $\mathrm{MH}$ and conventional dressings. Therefore, the purpose of this present study in this area was different from that of the previous studies [37-39]. In our pilot study, each group contained DFU relatively "good response" and "poor response" to the topical dressings; this may counteract the mean concentration of those biomarkers in each group. This was the possible reason why different results were obtained comparing with the published studies.

To the best of our knowledge, this was the first attempt to compare the serial changes of these biomarkers with the wound healing status. The result from the present study in this area was preliminary, so further studies with different topical interventions to confirm the result were recommended. Importantly, the investigation into the changes of biomarkers in wound fluid is increasingly popular for the prediction of wound healing. Therefore, there is a need for further researches to clarify any confounder to affect the concentration of biomarkers; otherwise, the creditability and effectiveness of measuring the biomarkers would be in question.

Importantly, the study results contributed to an evidencebased practice for DFU management. Traditionally, the use of dressing materials is mostly based on the clinical judgment of front-line health care providers. Now, this study has provided evidence on the $\mathrm{nAg}$ dressing that is potentially better in ulcer healing in terms of ulcer size reduction than the $\mathrm{MH}$ and conventional dressings, allowing professionals to select this effective dressing to promote DFU healing in their daily practice.

\section{Conclusion}

In the present study, the baseline characteristics were comparable among groups. All subjects received debridement from the same investigator using standard off-loading techniques. According to the preliminary findings, the authors concluded that the $\mathrm{nAg}$ dressing was potentially effective, while $\mathrm{MH}$ was only potentially, marginally effective in treating DFU. The preliminary findings in this study suggested a full study should be valid for and worth further investigations. In addition, the acute healing ulcer and ulcer having received serial debridement may not be suitable for comparing the chosen biomarkers to assess the healing status.

The small sample size was the major limitation in our study. The types of ulcers and the stages of acuteness were different among the three groups although there was no overall significant difference. This may create possible random bias in our samples. Nonetheless, the positive preliminary result on the ulcer reduction rate indicates that a clinic trial of larger scale is warranted in order to support the present findings. Another limitation was the insufficient censor points to examine the complete ulcer healing among groups. In our study, there were only nine observations throughout the 12 weeks and it may not be accurate enough to assess the actual healing time. This may explain why 
there was no significant difference detected among groups although the $\mathrm{nAg}$ group saw an obvious, higher cumulative healing incidence. Besides, the small sample size made it impossible to perform detailed bacteriology analysis on both number and types of species of bacteria although $\mathrm{nAg}$ showed the greatest decreasing trend in the number of species of microorganism. Finally, we demonstrated that nAg dressing is potentially better for DFU healing in terms of the ulcer size reduction rate as compared with $\mathrm{MH}$ and conventional dressings. The results of this clinical randomized trial shed new light on the practice, especially for clinicians, on the use of $\mathrm{nAg}$ dressing in DFU. It can also serve as a foundation for future's study on nAg and the related molecular biology on DFU healing.

\section{Competing Interests}

The authors declare that there is no conflict of interests regarding the publication of this paper.

\section{Authors' Contributions}

Ka-Kit Tsang wrote the manuscript. Enid Wai-Yung Kwong, Tony Shing-Shun To, Joanne Wai-Yee Chung, and Thomas Kwok-Shing Wong reviewed the manuscript.

\section{References}

[1] F. R. Martínez-De Jesús, "A checklist system to score healing progress of diabetic foot ulcers," International Journal of Lower Extremity Wounds, vol. 9, no. 2, pp. 74-83, 2010.

[2] International Diabetes Federation, IDF Diabetes Atlas, IDF, Brussels, Belgium, 6th edition, 2013.

[3] Y.-J. Chu, X.-W. Li, P.-H. Wang et al., "Clinical outcomes of toe amputation in patients with type 2 diabetes in Tianjin, China," International Wound Journal, vol. 13, no. 2, pp. 175-181, 2016.

[4] B. A. Lipsky, E. J. G. Peters, A. R. Berendt et al., "Specific guidelines for the treatment of diabetic foot infections 2011," Diabetes/ Metabolism Research and Reviews, vol. 28, S1, pp. 234-235, 2012.

[5] A. J. van den Berg, E. van den Worm, H. C. Q. van Ufford, S. B. Halkes, M. J. Hoekstra, and C. J. Beukelman, "An in vitro examination of the antioxidant and anti-inflammatory properties of buckwheat honey," Journal of Wound Care, vol. 17, no. 4, pp. 172-178, 2008.

[6] R. G. Sibbald and K. Y. Woo, "The biology of chronic foot ulcers in persons with diabetes," Diabetes/Metabolism Research and Reviews, vol. 24, no. 1, pp. S25-S30, 2008.

[7] J. L. Sare, "Leg ulcer management with topical medical honey," British Journal of Community Nursing, vol. 13, no. 9, pp. S22-S26, 2008.

[8] I. Sondi and B. Salopek-Sondi, "Silver nanoparticles as antimicrobial agent: a case study on E. coli as a model for Gramnegative bacteria," Journal of Colloid \& Interface Science, vol. 275, no. 1, pp. 177-182, 2004.

[9] K. M. Aparna Mani, S. Seethalakshmi, and V. Gopal, "Evaluation of in-vitro anti-inflammatory activity of silver nanoparticles synthesised using piper nigrum extract," Nanomedicine \& Nanotechnology, vol. 6, article 268, 2015.
[10] J. Stephen-Haynes, "Evaluation of a honey-impregnated tulle dressing in primary care," British Journal of Community Nursing, pp. S21-S27, 2004.

[11] M. D. Mandal and S. Mandal, "Honey: its medicinal property and antibacterial activity," Asian Pacific Journal of Tropical Biomedicine, vol. 1, no. 2, pp. 154-160, 2011.

[12] C. J. Adams, C. H. Boult, B. J. Deadman et al., "Isolation by HPLC and characterisation of the bioactive fraction of New Zealand manuka (Leptospermum scoparium) honey," Carbohydrate Research, vol. 343, no. 4, pp. 651-659, 2008.

[13] P. H. S. Kwakman, A. A. te Velde, L. de Boer, C. M. J. E. Vandenbroucke-Grauls, and S. A. J. Zaat, "Two major medicinal honeys have different mechanisms of bactericidal activity," PLoS ONE, vol. 6, no. 3, Article ID el7709, 2011.

[14] Y. Kato, N. Umeda, A. Maeda, D. Matsumoto, N. Kitamoto, and H. Kikuzaki, "Identification of a novel glycoside, leptosin, as a chemical marker of manuka honey," Journal of Agricultural and Food Chemistry, vol. 60, no. 13, pp. 3418-3423, 2012.

[15] C. W. Chan, B. J. Deadman, M. Manley-Harris, A. L. Wilkins, D. G. Alber, and E. Harry, "Analysis of the flavonoid component of bioactive New Zealand mānuka (Leptospermum scoparium) honey and the isolation, characterisation and synthesis of an unusual pyrrole," Food Chemistry, vol. 141, no. 3, pp. 1772-1781, 2013.

[16] M. Al Saeed, “Therapeutic Efficacy of conventional treatment combined with manuka honey in the treatment of patients with diabetic foot ulcers: a randomized controlled study," The Egyptian Journal of Hospital Medicine, vol. 53, pp. 1064-1071, 2013.

[17] A. V. Kamaratos, K. N. Tzirogiannis, S. A. Iraklianou, G. I. Panoutsopoulos, I. E. Kanellos, and A. I. Melidonis, "Manuka honey-impregnated dressings in the treatment of neuropathic diabetic foot ulcers," International Wound Journal, vol. 11, no. 3, pp. 259-263, 2014.

[18] A. Cahn and Y. Kleinman, "A novel approach to the treatment of diabetic foot abscesses-a case series," Journal of Wound Care, vol. 23, no. 8, pp. 394-399, 2014.

[19] B. A. Lipsky, A. R. Berendt, P. B. Cornia et al., "2012 infectious diseases society of America clinical practice guideline for the diagnosis and treatment of diabetic foot infections," Clinical Infectious Diseases, vol. 54, no. 12, pp. el32-e173, 2012.

[20] M. A. Hertzog, "Considerations in determining sample size for pilot studies," Research in Nursing and Health, vol. 31, no. 2, pp. 180-191, 2008.

[21] C. A. Fries, Y. Ayalew, J. G. Penn-Barwell, K. Porter, S. L. A. Jeffery, and M. J. Midwinter, "Prospective randomised controlled trial of nanocrystalline silver dressing versus plain gauze as the initial post-debridement management of military wounds on wound microbiology and healing," Injury, vol. 45, no. 7, pp. 1111-1116, 2014.

[22] F. Gottrup, B. M. Cullen, T. Karlsmark, M. Bischoff-Mikkelsen, L. Nisbet, and M. C. Gibson, "Randomized controlled trial on collagen/oxidized regenerated cellulose/silver treatment," Wound Repair and Regeneration, vol. 21, no. 2, pp. 216-225, 2013.

[23] C. N. Miller, N. Newall, S. E. Kapp et al., "A randomizedcontrolled trial comparing cadexomer iodine and nanocrystalline silver on the healing of leg ulcers," Wound Repair \& Regeneration, vol. 18, no. 4, pp. 359-367, 2010.

[24] W. White, "Sharp wound debridement in the management of recalcitrant, locally infected chronic venous leg ulcers: a narrative review," Wound Practice and Research, vol. 19, no. 4, 2011. 
[25] C. E. Bradshaw, "An in vitro comparison of the antimicrobial activity of honey, iodine and silver wound dressings," Bioscience Horizons, vol. 4, no. 1, pp. 61-70, 2011.

[26] D. G. Metcalf and P. G. Bowler, "Biofilm delays wound healing: a review of the evidence," Burns \& Trauma, vol. 1, no. 1, pp. 5-12, 2013.

[27] E. A. Rayment, Z. Upton, and G. K. Shooter, "Increased matrix metalloproteinase-9 (MMP-9) activity observed in chronic wound fluid is related to the clinical severity of the ulcer," The British Journal of Dermatology, vol. 158, no. 5, pp. 951-961, 2008.

[28] K. Moore, E. Huddleston, M. C. Stacey, and K. G. Harding, "Venous leg ulcers-the search for a prognostic indicator," International Wound Journal, vol. 4, no. 2, pp. 163-172, 2007.

[29] A. D. Widgerow, "Chronic wound fluid-thinking outside the box," Wound Repair and Regeneration, vol. 19, no. 3, pp. 287-291, 2011.

[30] E. A. Rayment, T. R. Dargaville, G. K. Shooter, G. A. George, and Z. Upton, "Attenuation of protease activity in chronic wound fluid with bisphosphonate-functionalised hydrogels," Biomaterials, vol. 29, no. 12, pp. 1785-1795, 2008.

[31] B. Cullen, R. Smith, E. Mcculloch, D. Silcock, and L. Morrison, "Mechanism of action of PROMOGRAN, a protease modulating matrix, for the treatment of diabetic foot ulcers," Wound Repair \& Regeneration, vol. 10, no. 1, pp. 16-25, 2002.

[32] K. Bahar-Shany, A. Ravid, and R. Koren, "Upregulation of MMP-9 production by TNF $\alpha$ in keratinocytes and its attenuation by vitamin D," Journal of Cellular Physiology, vol. 222, no. 3, pp. 729-737, 2010.

[33] S. J. M. Yussof, E. Omar, D. R. Pai, and S. Sood, "Cellular events and biomarkers of wound healing," Indian Journal of Plastic Surgery, vol. 45, no. 2, pp. 220-228, 2012.

[34] R. F. Diegelmann and M. C. Evans, "Wound healing: an overview of acute, fibrotic and delayed healing," Frontiers in Bioscience, vol. 9, pp. 283-289, 2004.

[35] N. J. Trengove, H. Bielefeldt-Ohmann, and M. C. Stacey, "Mitogenic activity and cytokine levels in non-healing and healing chronic leg ulcers," Wound Repair \& Regeneration, vol. 8, no. 1, pp. 13-25, 2000.

[36] R. Moseley, J. R. Hilton, R. J. Waddington, K. G. Harding, P. Stephens, and D. W. Thomas, "Comparison of oxidative stress biomarker profiles between acute and chronic wound environments," Wound Repair \& Regeneration, vol. 12, no. 4, pp. 419429, 2004.

[37] R. Lobmann, A. Ambrosch, G. Schultz, K. Waldmann, S. Schiweck, and H. Lehnert, "Expression of matrix-metalloproteinases and their inhibitors in the wounds of diabetic and non-diabetic patients," Diabetologia, vol. 45, no. 7, pp. 1011-1016, 2002.

[38] M. Muller, C. Trocme, B. Lardy, F. Morel, S. Halimi, and P. Y. Benhamou, "Matrix metalloproteinases and diabetic foot ulcers: the ratio of MMP-1 to TIMP-1 is a predictor of wound healing," Diabetic Medicine, vol. 25, no. 4, pp. 419-426, 2008.

[39] Y. Liu, D. Min, T. Bolton et al., "Increased matrix metalloproteinase-9 predicts poor wound healing in diabetic foot ulcers: response to Muller et al.," Diabetes Care, vol. 32, no. 11, p. e137, 2009. 


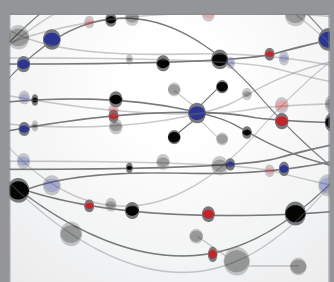

The Scientific World Journal
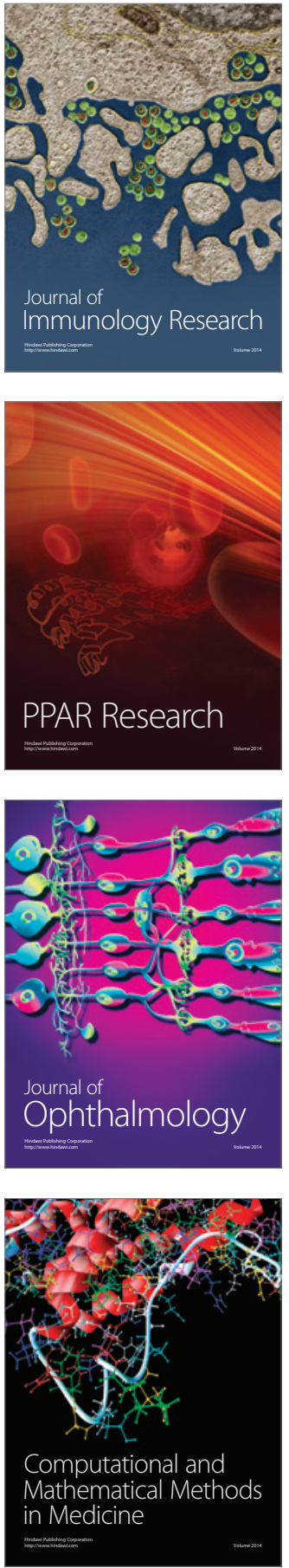

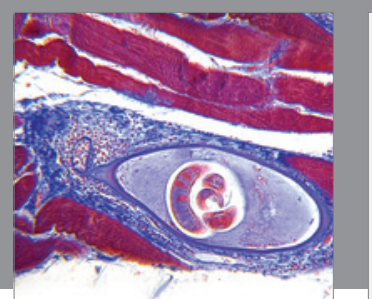

Gastroenterology Research and Practice
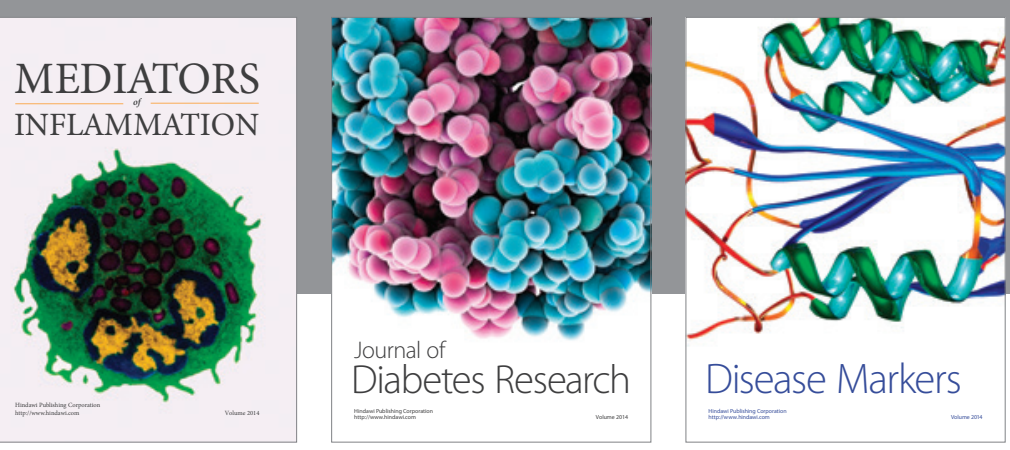

Disease Markers

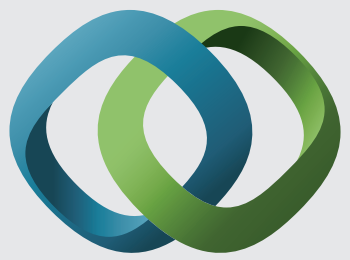

\section{Hindawi}

Submit your manuscripts at

https://www.hindawi.com
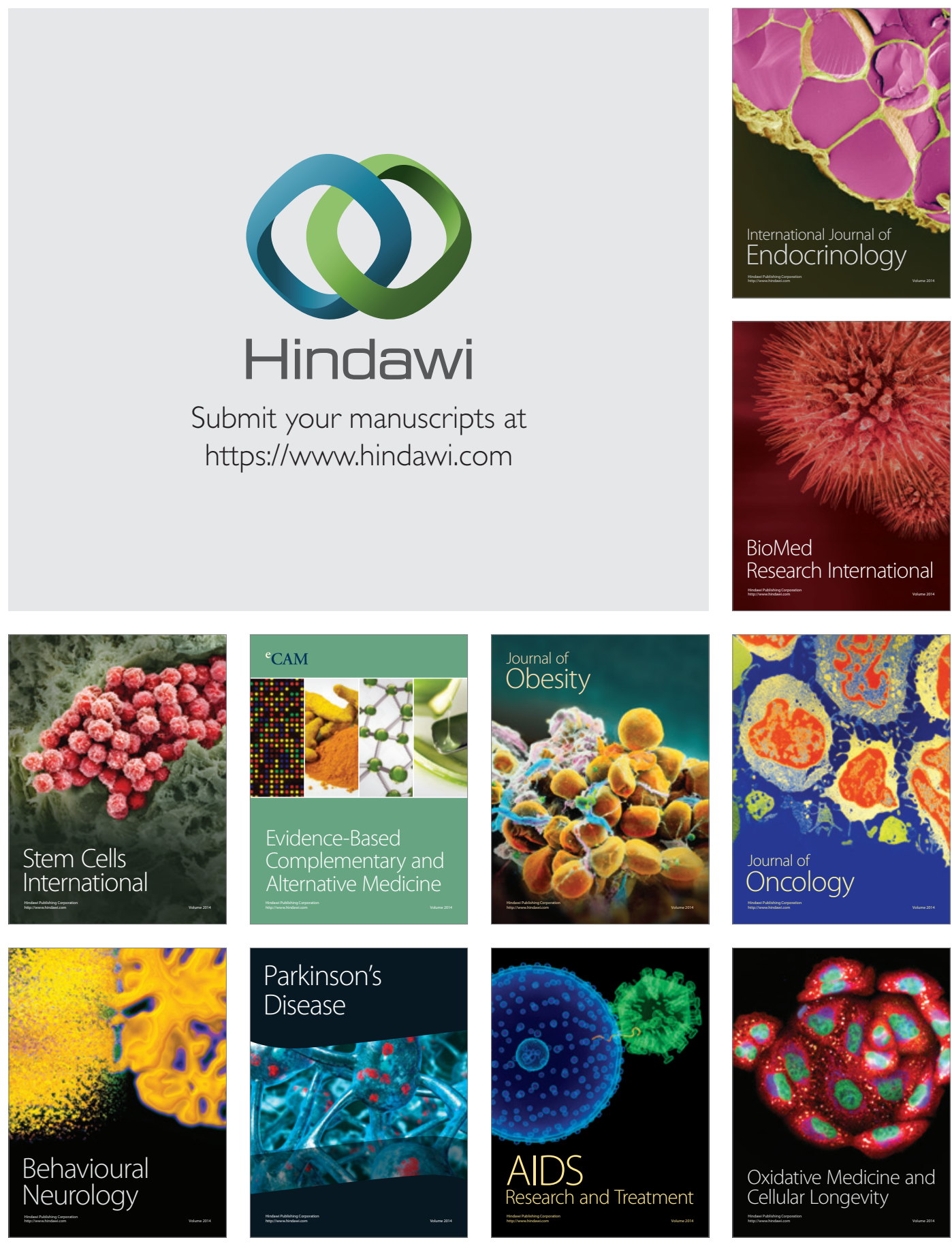